Illinois State University

ISU ReD: Research and eData

Theses and Dissertations

6-25-2021

\title{
Perceived Discrimination and Emotional Distress Experienced by Queer vs Heterosexual People of Color, Moderated by Perceived Distal or Proximal Social Support
}

Sanjana Satishkumar

Illinois State University, sanjana.satish15@gmail.com

Follow this and additional works at: https://ir.library.illinoisstate.edu/etd

\section{Recommended Citation}

Satishkumar, Sanjana, "Perceived Discrimination and Emotional Distress Experienced by Queer vs Heterosexual People of Color, Moderated by Perceived Distal or Proximal Social Support" (2021). Theses and Dissertations. 1466.

https://ir.library.illinoisstate.edu/etd/1466

This Thesis is brought to you for free and open access by ISU ReD: Research and eData. It has been accepted for inclusion in Theses and Dissertations by an authorized administrator of ISU ReD: Research and eData. For more information, please contact ISUReD@ilstu.edu. 


\section{PERCEIVED DISCRIMINATION AND EMOTIONAL DISTRESS EXPERIENCED BY \\ QUEER VS HETEROSEXUAL PEOPLE OF COLOR, MODERATED BY PERCEIVED \\ DISTAL OR PROXIMAL SOCIAL SUPPORT}

\section{SANJANA SATISHKUMAR}

\section{Pages}

This study examined QPOC experiences of discrimination and emotional distress and buffering roles of proximal social support and distal social support. Specifically, we hypothesized (a) QPOC would experience more discrimination and higher distress than straight people of color (SPOC) due to their double minoritized status; (b) QPOC would have similar proximal but (b-2) lower distal support compared to SPOC; and (c) social support would moderate the relationship between discrimination and distress among QPOC, such that this link will be weakened when social support is higher. 206 participants of color (156 straight, 50 queer) completed the online survey of this study. Independent sample t-tests revealed that QPOC reported significantly higher discrimination, $\mathrm{t}=-3.14, \mathrm{p}=.002$, and distress, $\mathrm{t}=-5.12, \mathrm{p}<.001$, and lower distal social support, $\mathrm{t}=-2.88, \mathrm{p}=.004$ than straight people of color supporting hypotheses (a) and (b-2). A moderated regression analysis using PROCESS MACRO v3.5 (Hayes, 2018) with perceived microaggression as IV, distress as DV, and proximal and distal support as moderators did not reveal significant interaction effects between discrimination and proximal support, $\beta=.02, \mathrm{p}=.93$, or distal support, $\beta=.5, \mathrm{p}=.85$. Results of the study support the hypothesis of queer people of color having higher discrimination, higher distress, and lower social support than heterosexual counterparts. No support was found on social support playing a 
buffering role in the relationship between discrimination and distress. More research needs to be conducted to find factors in queer people of colors' lives that help reduce distress.

KEYWORDS: discrimination; distress; queer people of color; intersectionality; social support 


\title{
PERCEIVED DISCRIMINATION AND EMOTIONAL DISTRESS EXPERIENCED BY QUEER VS HETEROSEXUAL PEOPLE OF COLOR, MODERATED BY PERCEIVED DISTAL OR PROXIMAL SOCIAL SUPPORT
}

\author{
SANJANA SATISHKUMAR
}

A Thesis Submitted in Partial Fulfillment of the Requirements for the Degree of MASTER OF SCIENCE

Department of Psychology ILLINOIS STATE UNIVERSITY 
(C) 2021 Sanjana Satishkumar 


\title{
PERCEIVED DISCRIMINATION AND EMOTIONAL DISTRESS EXPERIENCED BY QUEER VS HETEROSEXUAL PEOPLE OF COLOR, MODERATED BY PERCEIVED DISTAL OR PROXIMAL SOCIAL SUPPORT
}

\author{
SANJANA SATISHKUMAR
}

COMMITTEE MEMBERS:

Suejung Han, Chair

Daniel G. Lannin 


\section{CONTENTS}

$\begin{array}{lr}\text { CONTENTS } & \text { Page } \\ \text { CHAPTER I: INTRODUCTION } & \text { i } \\ \end{array}$

CHAPTER II: LITERATURE REVIEW

Discrimination and Intersectionality of Identities 4

Intersectionality of Multiple Marginalized Identities $\quad 8$

Queer People of Color and Enhanced Coping 17

Social Support as Buffer Against Discrimination 19

Perceived Social Support for Queer People of Color 20

$\begin{array}{ll}\text { Present Study } & 24\end{array}$

$\begin{array}{ll}\text { CHAPTER III: METHOD } & 28\end{array}$

$\begin{array}{ll}\text { Participant Recruitment } & 28\end{array}$

$\begin{array}{ll}\text { Participants } & 28\end{array}$

$\begin{array}{ll}\text { Measures } & 29\end{array}$

Data Analytic Procedure 33

CHAPTER IV: RESULTS

$\begin{array}{ll}\text { Hypothesis Testing } & 38\end{array}$

$\begin{array}{ll}\text { CHAPTER V: DISCUSSION } & 40\end{array}$

Proximal versus Distal Support for Queer People of Color $\quad 40$

Social Support Not Buffering Impact of Discrimination for Queer People of Color $\quad 44$ 
Strengths, Limitations and Future Research

Conclusion 


\section{CHAPTER I: INTRODUCTION}

The present study focused on the intersectionality of racial/ethnic and queer identities and how multiple identities are linked to perceived discrimination and emotional distress.

Discrimination refers to oppressive systems and behaviors against a person, group of persons, or a community due to their minoritized identity or status related to race, sexuality, gender, or other dimensions (Krieger, 1999). Discrimination often reflects a belief in superiority of one group over others, and such hierarchy is based on unjustified stereotypes and prejudices (Williams et al., 1997). Discriminatory beliefs may lead to, or coincide with, prejudicial treatment of marginalized groups through legal systems or social etiquettes. Examples include the Jim Crow laws (i.e., anti-black laws that helped legalize the segregation and the subjugation of black people after the abolishment of slavery), or unofficial social laws such as not hiring women for higher positions at work based on the stereotype that women are not fit to be leaders. These discriminations further oppress minority subgroups and maintain the status quo and majority's privileges. There is much research that shows a correlation between discrimination and emotional distress for ethnic and sexual minorities (Salvatore \& Shelton, 2007; Williams et al., 1997), especially when they do not have support in their lives to help cope with it (Frost et al., 2016; Sue et al., 2020).

Discrimination can take various forms depending on the contexts, subgroups involved, and relevant legal protections (Williams et al., 1997). For example, individuals with queer identities can be fired from a job due to the lack of legal protection. Interpersonally, the person could hear slurs or offensive questions regarding sexuality, or experience violence against them (Capodilupo \& Sue, 2007; Nadal et al, 2011). They could also have to endure more subtle and relatively minor yet detrimental offenses, often referred to as microaggressions. 
Since the 1980s, overt discrimination had generally reduced whereas microaggressions became more commonplace, as blatant discrimination was considered to be increasingly socially unacceptable (Capodilupo \& Sue, 2007). However, there had been a gradual increase in antiblack sentiment since the election of Obama, which was further exacerbated with the 2016 U.S. presidential campaign and election (Duran, 2019; Stein \& Allcorn, 2018). Especially since the 2016 elections, blatant homophobia, xenophobia, and racism have dramatically increased, and transgender and queer rights have been under attack as well (Gonzalez, 2018). The most recent pride marches were closer to the historic origin of protesting against police brutality and homophobia than a party of acceptance and pride about themselves and their community. Gonzalez et al. (2018) reported that people with minoritized identities, particularly racial/ethnic minorities and sexual minorities have experienced much increased discrimination since the election due to normalization of prejudice towards groups Trump has targeted (Crandall et al., 2018). Thus, it is crucial to examine their continued and increased experiences of discrimination, its detrimental impact on their psychological well-being, and potential protective factors that could mitigate it, such as social support.

Social support is well-established as a protective factor against the detrimental effect of racial discrimination for racial/ethnic minorities (Brown, 2008). Specifically, research showed that seeking social support was effective in reducing distress from racial discrimination. In general, social support can come from family, friends, and significant others (Hefner \& Eisenberg, 2009; House et al, 1988) as well as neighborhood/community and church/religious groups (Herrero \& Gracia, 2007). However, it is not well-established the level to which queer people of color access community support and support from close individuals due to heterosexism, racism, or both. 
Intersectionality theory focused on intersections of privileged and minoritized identities and how experiences differ based on these intersections (Crenshaw, 1989). For example, a queer Asian woman may face discrimination based on her sexuality, race, or gender. Alternatively, she may face a unique discrimination that is aimed towards all these minoritized identities together. Those with double minoritized status could lead to increased experiences of discrimination (Meyer, 2003) and yet limited social support (Frost et al, 2016). The intersectionality of identities and their unique experiences have received increased scholarly attention only recently.

This study focused on intersectionality racial/ethnic and queer identities and the experiences of discrimination and social support for queer people of color with multiple minoritized identities. Research shows that social support is a crucial protective factor against racism for racial/ethnic minorities (Brondolo et al., 2009) and against homophobia/transphobia for queer individuals (Doty et al., 2012). However, research is still lacking in how social support is used by queer people of color. In fact, due to homophobia/transphobia among racial/ethnic minorities (Balsam et al, 2011) and racism within queer communities (Balsam et al, 2011), queer people of color may not receive as much social support that they need compared to individuals with one minoritized identity (i.e., straight people of color or White queer people). Thus, I examined how two different types of social support—proximal support from family, friends, and significant other and distal support from the larger community (e.g., racial/ethnic or queer community) could mitigate the detrimental impact of discrimination on psychological well-being of queer people of color. 


\section{CHAPTER II: LITERATURE REVIEW}

The present chapter provides a review the literature on the intersectionality of multiple identities in general as well as empirical findings on the intersectionality between racial/ethnic identity and queer identity in particular. A review on the role of social support as a buffer/protective factor against racial/sexual discrimination follows. The rationales for the current study and specific hypotheses conclude this chapter.

\section{Discrimination and Intersectionality of Identities}

Discrimination refers to oppressive systems and behaviors against a person, group of persons, or a community due to their minoritized identity or status related to race, sexuality, gender, or other dimensions (Krieger, 1999). While discrimination is a well-researched topic, the different types of discrimination often are researched individually, rather than taking a holistic perspective that researches how different types of discrimination combine and coexist.

Intersectionality theory, first introduced by Kimberly Crenshaw (1989), proposes that all individuals have a multitude of social identities that are interdependent and not mutually exclusive (Bowleg, 2013). That is, race, class, gender, sexuality, and other cultural dimensions that define identities are all interconnected and need to be examined as such to obtain a complete view of both the identities and the individuals. For example, race and sex needs to be viewed in relation to each other to completely understand the experiences of Black women in comparison to others, because being black cisgender women involves qualitatively different experiences than being black in general or being a cisgender man, a non-black woman, or transgender black woman. Britney Cooper, author of Eloquent Rage (2018), explains how black women are not allowed to explore and show their rage as it would reinforce the stereotype of black women being loud and angry. Although White women are also often invalidated by men when 
expressing their anger, their expression is more accepted socially and less judged negatively compared to that of Black women. In the case of Black men, anger expression would be likely to face police brutality or much harsher discrimination than that of White men, White women, or Black women.

As such, these identities influence each other as well as the experiences of an individual and form a unique reality, rather than independently influencing lived experiences of the individual (Bowleg, 2013). For example, a queer Hispanic man might be influenced by his ethnicity and his sexuality; however, his ethnicity's cultural expectations and beliefs about same sex attraction might also influence his understanding and experiences of her queerness, and vice versa. If he grew up in a traditional conservative family, he may have strict gender roles and expectations of machismo to live up to (Eaton \& Rios, 2016), he may not accept his sexuality until young adulthood or older, he may be religious which might further influence his beliefs on sexuality. Conversely, because he is queer, he may have grown up constantly worrying about being outed to his family; he may have felt like he would need to choose between his sexuality or his culture and whether his parents might truly accept him and might grow distant to his extended family and create a friend-family of other queer Hispanic individuals. All of these experiences would not be completely experienced by heterosexual Hispanic men or queer White men - as these identities influence each other to create a unique experience.

Intersectionality is often overlooked in understanding identities because of the biased assumption that a normative prototype of each social category is and should be the most dominant identity ascribed by the society (Purdie-Vaughns \& Eibach, 2008). That is, prototypical members are the dominant subgroup of the social category that are considered to be the norm for said category. For example, due to androcentrism (males as the norm), 
heterocentrism (heterosexuality as the norm), and ethnocentrism (White race and European American ethnicity as the norm), heterosexual men are considered as the prototype of Black identity, White heterosexual women are considered as the prototype of women, and White homosexual men are considered as the prototype for the queer community. In fact, early feminist scholars have been criticized for reducing women's issues to "white women's issues", demonstrating their bias that a normative, prototypical group of women is White (Crenshaw, 1989). Despite the fact that the Stone Wall riot (1969) and the early queer rights movements was led by a Black transgender woman (Beemyn, 2013), White male queer leaders and their work have received the most scholarly and social attention, demonstrating the biased assumption that a normative, prototypical group of Queer are White cisgender males (Purdie-Vaughns \& Eibach, 2008).

Ignoring intersectionality of identities results in detrimental consequences at many levels. For individuals, the assumption of dominant normative prototypes in each social category can erase, invalidate, and misrepresent the experiences of those who lie outside these normative prototypes of social categories. The intersectional experiences due to the interlinked identities are erased as they do not fit the experience of the dominant normative prototypes of a singular identity, thereby resulting in ostracization or rejection of multiple minority individuals (PurdieVaughns \& Eibach, 2008). For example, due to the erasure of queer black individuals in history and media, Black identity is separated from and thought to not co-exist with the LBGT+ community (Stone \& Ward, 2011). This misconception can cause distress to many Black queer individuals who might be questioning or in the process of accepting their identity. Another example is the recent mainstream film Stonewall (2015) where trans Black women's activities like Marsha P. Johnson were erased and misrepresented because an all-White, cisgender male 
cast was hired to depict the historic event. This perpetuated the misrepresentation that White gay men were the propagators of queer rights movement rather than giving voice and visibility to intersectional minorities. This also deprives individuals with intersectional identities of opportunities to learn, take credits from, and further develop their positive regard to their own history. Thus, some queer racial/ethnic minority individuals may wrongfully feel that they may not belong to the queer community. Additionally, this erasure could create political invisibility and thus prevent or hinder the civil rights of multiple-minoritized communities (Purdie-Vaughns \& Eibach, 2008).

At the institutional level, this assumption can lead to various unjust policy, practice, and legal consequences. For example, Crenshaw (1989) described a real judicial example of a Black woman going to court over discrimination as a Black woman in her paper describing and explaining intersectionality. This case, however, was dismissed because the company had previously hired Black men and White women. This reflects a lack of understanding of the core of her case: it is the intersecting identity of her race and gender, being both Black and a woman, that is causing the prejudice she is experiencing, not being Black or a woman. Another judge dismissed a similar discrimination case because the discrimination was "only for a black female" rather than women in general (p. 114). That is, this case is not a gender discrimination case because it was only for a Black female that does not prototypically represent the entire women group. This example again shows the bias against Black women which may not be shown against Black men or White women.

For scholars and practitioners, lack of considering intersectionality in examining identities can result in biases in research and failure to serve marginalized groups effectively. For example, research samples may not be appropriately representative, and the results may not be 
generalizable to the underrepresented subgroups. Such findings may not be useful in informing best practices or needed services for the individuals or subgroups. In fact, ill-informed services (e.g., psychotherapies) could further harm clients with multiple minoritized identities (e.g., feeling invalidated by their therapist) (Ratts, 2017). In sum, intersectionality of identities should be considered in understanding experiences of identities. Failing to do so can result in subjective distress and missed opportunities for individuals, support and perpetuate biased policies and procedures, and misguided research and practices.

\section{Intersectionality of Multiple Marginalized Identities}

Intersectionality of multiple marginalized identities adds complexities to the issue, because people with such identities do not belong to the 'normative' prototype of any of the social categories with which they identify. Two opposing hypotheses exist on how individuals with multiple minoritized identities experience discrimination and oppression (Purdie-Vaughns \& Eibach, 2008). The first hypothesis, referred to as double-jeopardy hypothesis (Ferraro \& Farmer, 1996), suggests that those with multiple minoritized identities experience more discrimination and disadvantages due to their identities, either additively or multiplicatively (Purdie-Vaughns \& Eibach, 2008). The second hypothesis, referred to as intersectional invisibility hypothesis (Purdie-Vaughns \& Eibach, 2008), states that people with multiple minorized identities face less discrimination, because they are not prototypes of each social category and therefore more invisible to oppressor groups. As reviewed above, prototypical people of color would be heterosexual men; prototypical women would be White heterosexual; and prototypical queer person would be White cisgender men. These prototypical subgroups in each social category are the most visible to the outer community and therefore face harsher and more discrimination than those who are overlooked and erased due to their less prototypicality. 
For example, queer people of color may face less heterosexism or homophobic treatment because of their sexuality is less visible to the heterosexist community due to their skin color. The following sections will illustrate these two competing hypotheses in detail.

Double Jeopardy Hypothesis. The double jeopardy hypothesis suggests that multiple minoritized individuals face more discrimination and experience higher levels of psychological distress (Hayes et al., 2011). For example, Balsam et al. (2011) reported that racism negatively impacted queer participants of color, especially when it was from partners and friends who were White. Similarly, Mays et al. (1993) suggested that racial discrimination while dating White lesbians led Black lesbians to seek other Black lesbians as romantic partners in the future. Balsam et al. (2011) also reported that heterosexism from racial/ethnic community caused higher psychological distress for queer people of color than racism from the queer community. The researchers suggested this might be due to queer people of color relying more on their ethnic community for support against racism (Lord, 1988). This is a situation that White queer individuals do not have to face.

The double jeopardy hypothesis proposes additive versus interactive models for explaining increased distress among people with double minoritized identities. The additive model views identities as separate and non-integrative (Purdie-Vaughns \& Eibach, 2008). The individual faces discrimination for each minority identity separately that would simply add up. For example, queer people of color may face racial discrimination not only from the society at large but also from the queer community that is predominantly White (Balsam, et. al, 2011). Balsam et al. (2011) argues that their queerness does not protect them from experiencing racism from the queer community (Duran, 2016). They also face homophobia not only from the society at large but also from their own racial/ethnic groups that are more heterosexist, whether they are 
open or closeted (e.g., insensitive derogatory sexual jokes). Researchers who adopted this model typically measured racial discrimination and heterosexist discrimination separately and added them to create an overall discrimination score (Balsam et al., 2011).

The interactive (or multiplicative) model, on the other hand, suggests that multiple minority identities cannot be viewed as individual identities and interact with each other to create a distinct experience from that of others with either singular identity (Purdie-Vaughns \& Eibach, 2008). For example, a queer person of color would experience discrimination for being both queer and a person of color simultaneously, which would be uniquely different from that of straight people of color or queer White individuals. For example, being an East Asian gay man may hear more derogatory slurs or experience harsher treatments for an Asian gay man at the same time, compared to straight Asian men or White gay men. (Capodilupo \& Sue, 2007; Nadal et al. 2011). He may face unique discrimination by being both gay and East Asian, such as being considered less masculine/more feminine by other Asian men for being gay or by non-Asian gay men for being Asian (Han, 2006; Han, 2007). This can cause mockery among the gay community as well as Asian community that often values masculinity, and an expectation of the Asian gay men performing certain gender or sexual roles. Researchers who adopted the multiplicative model developed measures that capture these unique intersections of identities, such as the LGBT-People of Color (POC) Microaggression Scale (Balsam et al., 2011).

Intersectionality Invisibility Hypothesis. On the contrary, the intersectional invisibility hypothesis (Purdie-Vaughns \& Eibach, 2008) states that people with multiple minoritized identities face less discrimination, because as non-prototypical members of each social identity group, their minorized identity often is invisible to outer oppressor groups. Supporting this hypothesis, research shows that people with a single minoritized identity and other dominant 
identities experienced harsher discrimination. For example, subordinate male target hypothesis (Purdie-Vaughns \& Eibach, 2008) developed based on the social dominance theory (Sidanius \& Pratto 1999) states that subordinate males, such as men of color, face harsher and/or more discrimination because they are more visible due to their dominant identity (i.e., being a man) as well as being subordinate within the said dominant class (Purdie-Vaughns \& Eibach, 2008). Pratto, Sidanius, and Levin (2006) state that this "collective violence... are almost exclusively instigated, organized, and controlled by men" (p. 274) and that men are the primary targets of said violence. The researchers provide further evidence as historically, men are more often the more likely to use lethal means and are both instigators and targets of murders related to race and sexuality than women. This does not negate the fact that women are abused or oppressed; however, they argue that the violence towards women occurs mainly to humiliate the women or emasculate the men related to the women. Additionally, studies show that Black men were reported to face higher employment discrimination and incarceration rates than White men, but this racial disparity was not found among women (Sidanius \& Pratto 1999; Simmons et al., 1991). It was interpreted as meaning that for Black women, their blackness was less visible because of their gender being subordinate as well. Ethnic minority men also report higher work discrimination within the past 30 days than ethnic minority women (Sidanius \& Pratto, 1999). Other studies did not support this hypothesis. Ifatunji et al. (2016) re-examined the previously mentioned rates of higher employment discrimination among Black men than Black women and concluded that gender bias in the measures misled the results. Also, Simmons et al. (1991) reported that men do not experience more discrimination necessarily, but they are more likely to report discrimination. Those who are in the dominant social categories may voice their concerns more freely and strongly, and often argue that they are the ones that face discrimination 
(Schmitt \& Branscombe, 2002). However, they had less risk to attribute an incident as discrimination or prejudice and had less serious examples when asked about being discriminated against. Additionally, attributing a situation as discrimination caused more emotional distress for minoritized groups than privileged groups (Schmitt \& Branscombe, 2002).

Another limitation of the subordinate male target hypothesis is that it failed to consider the interdependence and interconnections between subgroups of a community (Purdie-Vaughns \& Eibach, 2008). For example, Black women have advocated and protested for the issues that Black men face but have criticized Black men for not reciprocating this advocacy to Black women's plights. Additionally, by being invisible, these sub-groups do not receive the support and resources that prototypical members might receive (Purdie-Vaughns \& Eibach, 2008). For example, although Black men may face higher rates of police brutality, Black women are also at risk for police brutality, yet their names and experiences are often unheard and forgotten (Chatelain \& Asoka, 2015). These women are often brutalized in a similar manner yet are invisible due to their double minority status.

In sum, the double jeopardy hypothesis is generally supported, but mixed findings exist for the intersectional invisibility hypothesis. Therefore, the current study examined multiple minority identity using the double jeopardy hypothesis because it has stronger empirical support, while also including both the additive and multiplicative forms of discrimination. This inclusion of multiplicative and additive forms in the study is because discrimination is a complex subject that can manifest additively or multiplicatively depending on various factors such as everyone being aware, the perpetrators own identities, social context, and numerous other factors

Intersectionality between Race and Sexuality and Discrimination. Despite the abundance of studies on single identity groups, researchers only recently began to address 
intersectionality. Many previous studies do not report separate findings of intersectional subgroups (Ratts, 2017). For example, scholars have criticized the lack of focus on queer people of color and the exclusive focus on White queer individuals in research (Barnett et al., 2019). A content analysis of psychological queer literature between 1990-1999 found that only $12 \%$ of articles were focused on queer people of color and their experiences (Phillip et. al, 2003). Barnett et al. (2019) found that research has been growing since then, with $21.5 \%$ of articles having an identified queer people of color participants in his content analysis, with $75 \%$ of the new additions published in the last decade. However, transgender people of color are still drastically underrepresented in the literature, providing further evidence of the need for intersectional research.

One unique aspect of the intersectionality between race/gender and sexuality is that race/gender is a visible identity, whereas sexuality could be largely invisible, and one can choose to be closeted. One could be hetero-passing if one chooses not to disclose due to various reasons (e.g., perceived unsafety of the environment, early sexual identity developmental status). Additionally, poly sexual people could also be hetero-passing if they date someone that is not of the same biological sex as them. This hetero-passing can provide a sense of physical safety and comfort particularly in homophobic environments, which racial/ethnic minorities could not entertain in racist spaces.

This forced awareness and visibility of skin-color in comparison to sexuality might render race/ethnicity more central to identity for queer people of color (Bowleg, 2013). While queer people of color would be aware of their sexuality in largely heterosexual, ethnic community spaces, it is not in the forefront of thought for many in the same way that their race is (Bowleg 2013; Patton, 2011). This heightened racial awareness is not experienced by White 
queer individuals, unless they are in a minority-majority space (i.e. a space where ethnic minority individuals become a numerical majority in comparison to white individuals). Even when they are in the numerical minority, they still maintain the societal power and privilege associated with Whiteness; they may be uncomfortable, but they are not oppressed for their race (Frye, 1983).

Double Jeopardy for Queer People of Color. The double jeopardy hypothesis suggests that queer people of color experience more discrimination (i.e., summation of racial discrimination and sexual discrimination—additive model) or harsher discrimination (i.e., discrimination due to having both marginalized identities simultaneously) that is greater and unique than the sum of racial and sexual discrimination (i.e., multiplicative model). Although not all studies adopted this hypothesis as a guiding framework, multiple studies have provided direct and indirect supports for this hypothesis. Both quantitative and qualitative studies have shown that that queer people of color face heterosexist and racist discrimination with various psychological and mental health consequences (Balsam et al., 2011; Shilo, \& Mor, 2014; Velez, et al., 2019), which was moderated by ethnicities, gender, and specific sexualities. Balsam and colleagues (2011) reported that queer people of color often face sexual objectification and fetishization (i.e., unique discrimination that is different from racial or sexual discrimination) and racism within the queer community when finding and dating partners. For example, many Grindr profiles often have preferences listed such as "Whites only" or, in contrast, fetishized descriptions of African Americans (Balsam et. al, 2011; Phua \& Kaufmann 2003).

Balsam et al.'s (2011) also reported that Asian American queer participants faced higher levels of racial microaggression and distress in their dating relationships than other ethnicities. This is consistent with previous research that found Asian American gay men to be least sexually 
desired by gay men of other ethnicities as well as their own ethnicity as partners due to femininized/submissive stereotypes attached to them (Wilson et al., 2009). This is related to the fact that masculinity tends to be valued in gay male culture as a counter-reaction to being stereotyped as effeminate by heterosexual society (Han, Proctor \& Choi, 2014). Wilson et al. (2009) found that Black men were viewed as masculine and "tops" whereas Asians were viewed as effeminate and "bottoms" and reported hearing derogatory remarks based on this view. This may reflect the negative racial stereotypes about ethnicities and sex in Western society.

Pittman et al. (2020) examined intimate partner violence among female college students and found that queer women in general were at a higher risk for physical, sexual, and emotional abuse from their partners than heterosexual women. More importantly, queer women of color had a higher risk for the intimate partner violence than White heterosexual, White queer, and heterosexual women of color (Pittman et al., 2020). Specifically, Latina queer women were at highest risk for facing emotional intimate partner violence, closely followed by Black queer women, compared to White and Asian American queer women. Both Latina and Black queer women were at more than $100 \%$ higher risk for intimate partner violence than their heterosexual counterparts or White counterparts.

Eaton and Rios (2017) examined the experiences of Latino queer men and their coming out experiences by conducting semi-structured interviews. The results showed that $68 \%$ of the participants experienced negative responses from others when they came out, with the negative responses coming from their mother (41\%), friends (32\%) followed by father and coworkers $(18 \%)$. The themes that emerged included loss of relationship (i.e., being rejected, ending the relationship), aggression (i.e., physical harm, displacement), pathologizing (i.e., their sexuality is a disease), and self-serving responses (how participant disclosure relates/means to them). The 
researchers explained that Latinx cultural values including deference to the elders, family orientation, emphasis on group harmony, and religiosity may be related to the difficulty during the coming out.

In an interview study with Black queer men, Bowleg (2013) found that participants reported racism being the foremost discrimination, whereas their sexuality could be hidden. A majority (10 out of 12) participants reported that they would rank their Black identity as the primary identity. This is consistent with previous studies (Christian, 2005; Patton, 2011) that suggest that queer people of color might perceive their race to be a more central identity due to its visibility, whereas sexuality can be revealed only if they feel safe to do so. In an interview with six Black queer men, Patton (2011) found that all 6 men felt hesitant when speaking about their sexuality and were selectively out, stating that their sexuality was not important during regular conversations.

Velez et al. (2019) also found that heterosexism and racism, as well as internalized heterosexism and racism, had a positive correlation with psychological distress. They also found significant interactions between internalized racism and both sexual and racial discrimination such that internalized racism was positively correlated with psychological distress only for low and average sexual and racist discrimination. This suggested that having low internalized racism might result in external attributions of discrimination, unless the discrimination is too high to ignore. However, a similar interaction between internalized heterosexism and racial or sexual discrimination was not found. This implies that different oppressions interact and influence each other for queer people of color.

Ramirez and Galupo (2019) also studied distal stress (external stress like microaggressions, discrimination) and proximal stress (internalized stress like self-identity, 
internalized homophobia) and its relation to mental health among queer people of color. Their perceived distal stress was negatively correlated with mental health and more strongly when both types of stress were combined. More importantly, they identified vicarious trauma/community trauma as a source for psychological distress. Participants experienced significant distress when they became aware of violence committed against others with queer and/or racial minoritized identity in their community (e.g., Orlando Pulse shooting incident).

\section{Queer People of Color and Enhanced Coping}

On the other hand, some researchers have argued that queer people of color may experience more discrimination but less distress because they develop coping skills for discrimination early on. For example, Black queer people may have received racial socialization at a young age to expect and cope with racism, which they could apply to heterosexism (Hayes et al, 2011; McConnell et al, 2018). Hayes et al. (2011) found that participants of color reported significantly more depression, hostility, and family concerns, and academic concern than their White counterparts, regardless or sexuality. Similarly, all queer participants reported significantly more depression, hostility, general and social anxiety, eating concerns, and family concerns than heterosexual counterparts, regardless of race. However, no significant difference in the overall mental health symptoms was found between White queer participants and queer students of color, except that queer students of color reported higher hostility. They suggested this might be due to queer students of color having coping mechanisms developed to address racism previously, which could have been used to address heterosexism as well, to alleviate some of the symptoms.

Lorenz et al. (2019) also found that White queer students had lower sense of belonging in their college (in terms of their sexuality) compared to Asian queer students. This might be due to 
Asian students having greater freedom to express themselves in college than their home communities. Another interpretation was that White queer students have had less experience with discrimination and may not know how to cope with it. They also may have limited understanding of intersectionality and limited ability to recognize White privilege, which could magnify the perception and experience of discrimination.

McConnell et al. (2018) compared White queer men and queer men of color in the associations between LGBT stigma in their neighborhood, connection to the LGBT+ community (i.e., feeling belonged to the community and receiving support from it), and stress. They found that the two groups did not differ on the levels of these variables, but the association between experiencing LGBT stigma and stress was stronger for White queer men. Also, connection to the LGBT community fully mediated the relationship between LGBT stigma and stress for White queer men but only partially for queer men of color. These findings were interpreted as meaning that queer men of color may have better coping skills with discrimination and thus experience less distress from LGBT discrimination. They also found that racial-ethnic stigma in the LGBT community was not associated with connection to the LGBT + community for queer people of color, suggesting that racial discrimination from the LGBT community did not deter them from connecting with the queer community, because they anticipate racism from any communities with which they interact. However, they did not differentiate between queer community of people of color and general queer community in this study. It is possible that queer people of color may feel connected to the former but be deterred from the latter due to racism, which warrants a future investigation.

It is possible that White queer participants often report higher perceived distress because they tend to over-report the prejudice they experience as opposed to people of color who tend to 
underreport or minimize the discrimination they experience. Underreporting may be partly in order to protect their mental well-being (McConnel et al., 2018), or they may find it harder to voice their concerns due to chronic invisibility as people of color (Asakura, 2016).

\section{Social Support as Buffer Against Discrimination}

Social support is one of many protective factors that can mitigate the impact of stress on various outcomes such as emotional distress, mental health, occupational functioning, or health (Frost et al., 2016). Social support can include instrumental (e.g., financial support, advice giving) and emotional (e.g., validation of distress) support. In general, social support can come from family, friends, and significant others (Hefner \& Eisenberg, 2009; House et al, 1988). In addition, other specific groups such as neighborhood/community and church/religious groups could provide communities of belonging and crucial social support (Herrero \& Gracia, 2007).

It is well-established that social support is crucial for mitigating the detrimental effect of racial discrimination for racial/ethnic minorities (Brown, 2008). Specifically, research showed that seeking social support was effective in reducing distress from racial discrimination (Brown, 2000). Zimmerman et al. (2000) found that social support from parents alleviated depression and anxiety among Black adolescents. Brown (2000) also found that receiving racial socialization and perceived social support significantly increased the resiliency of Black college students. In fact, even the existence of one supportive individual could be beneficial to the health and resilience among Black people (Constantine, 2003).

Literature also has shown that social support could be crucial in protecting mental health and psychological well-being for people with sexual and gender queer identity (Frost et al., 2016). Studies have found that social support for queer individuals is correlated with reduced depression, anxiety, suicidal ideations, and reduced self-esteem (Liu \& Mustanski, 2012; 
Mustanski, et al., 2011, 2013). However, research shows that queer adolescents report lower social support and higher psychological distress (Bos et al., 2008). It may be partly because they do not have accessible role models and queer adults to gain support or queer socialization from, despite increased coming out rates in this decade (Bird et al., 2012). Bird et al. (2012) found that $60 \%$ of the queer adolescent participants had inaccessible role models (i.e., celebrities, politicians, etc.), with Black participants having the highest rates of inaccessible role models (43\%) in comparison to White (37\%) or Latino (39\%) participants. The study found that psychological distress was higher for those with inaccessible role models than either no role models or accessible role models. The researchers stated that having inaccessible role model might be a reminder of the lack of social support in their lives, as well as not being able to access their role models causing distress.

\section{Perceived Social Support for Queer People of Color}

Social support as resources and buffer has not been examined directly among queer people of color. Social support can be more limited for them. First, the number of people who fully understand the unique experiences of racial and sexual intersectionality is limited and thus less likely to be available as a support. Second, some support such as family, friends, church community or neighbors may disapprove their sexuality upon coming out. Even while they try to accept, there still could be subtle tension and discomfort (Bowleg, 2013; Rios \& Eaton, 2016), rendering their support unavailable. Third, the racial/ethnic community that provides support against racism may not do so against homophobia/transphobia. Similarly, the queer community that provides support against homophobia/transphobia for others may not offer support for queer people of color due to racism. 
For example, Ghabrial (2017) reported that queer people of color would perceive less support from their ethnic or queer communities. She interviewed 11 community-recruited queer people of color in Canada and examined their sense of belonging. She found that 8 out of 11 participants felt disconnected from their ethnic communities due to their sexual identity. Four felt disconnected from both their ethnic and queer communities, due to racism encountered in the queer community. Six felt excluded and thus avoided participating in queer events. Five preferred to interact exclusively with queer people of color and experienced fewer microaggressions, more support, and subsequent better well-being. Additionally, many participants reported feeling that queer identities are associated with Whiteness and queer people of color were underrepresented in the queer media. These results suggest that they perceive limited support from ethnic or queer communities.

On the other hand, Rios and Eaton (2016) interviewed Hispanic queer college men and found they perceived support from their family. Approximately $79 \%$ of the participants perceived support from both heterosexual and queer men family members (e.g., fathers, uncles, brothers, cousins). Seventy-five percent perceived support from women family members, but they did not specify the sexuality of women family members in their responses, suggesting salience of sexuality of men family members. It may be related to Hispanic cultural emphasis on machismo' and resulting anticipation of more rejection from men for their sexuality. The four themes from the interviews included shared experience ( $46 \%$; i.e., having previous experience with queer support or being queer), protector ( $42 \%$; i.e., support by protective behaviors/emotions), support in the air (33\%; i.e., indirect gestures of support/situational support), and gradual support (29\%; initial rejection and becoming accepting and supportive over time). The protector theme often included reports of brothers who supported participants against 
rejecting parents, and women family members who were concerned about negative reactions against participants and their physical and mental health. Additionally, many mentioned being apprehensive of coming out to their family. These findings suggest that despite available family support, they still experience negative reactions that warranted protection from supportive family members.

Murray et al. (2018) demonstrated that Black and Latino queer men perceived their racial/ethnic culture to be homophobic and feared losing their social support if they disclosed their sexuality. In this interview study, the participants reported experiencing homophobia that prevented them from disclosing their sexuality, which in turn led to risky behaviors such as having sex with strangers and not educating themselves regarding safe sex. Because of fear of losing friends and family, they felt like they had no one to talk to or reprimanded about their risky behaviors.

Additionally, Sadika et al. (2020) reported that many queer people of color reported feeling disconnected with their ethnic community from a young age due to their sexuality, leading to limited social support. In this meta-analysis on Canadian queer people of color literature, it was demonstrated that queer people of color longed for freedom from parents to explore their sexuality and yet missed the presence of their parents while doing so, partly due to their cultural values of collectivism and interdependence. This absence of connection was especially felt strongly by immigrant participants of the studies examined, as Sadika et al. (2020) stated that second generation immigrants often have more outside sources of support they can lean on. While there were participants in the studies that reported positive experiences in coming out to their ethnic communities, the majority of participants experienced high perceived discrimination, and many reported the need to be closeted if they wished to stay connected to 
their community. However, due to the emphasis of coming out held in Western queer culture, that made them feel disconnected from the queer community. This perceived homophobia in racial ethnic groups may prevent queer people of color to come out to their family. Sadika et al. (2020) found that many participants expressed avoidance of home and ethnic community to avoid heterosexist discrimination.

Sometimes homophobia within a racial/ethnic community is closely associated with gender role ideology and religiosity. Black churches hold significant influence in Black communities and have been found to directly, or indirectly, cultivate homophobia (Ward, 2005). It is important to note that churches being a source of homophobia within a community is not specific to Black communities alone. Bowleg (2013) and Fields et al. (2015) found that Black queer men perceived Black church communities as non-accepting due to the traditional views of Christianity. Black queer men felt a pressure to conform to hypermasculine gender role expectations, which has been linked with psychological distress (Fields et al., 2015). Part of their perception of masculinity included perusing women and being physically strong. The Black gay participants reported that people close to them considered being gay a threat to masculinity and Black male gender role due to its association with being effeminate and therefore with being weak. Thus, they hid their sexuality, avoided femininity, and conformed to hypermasculinity to fit in, fearing losing social support. Similarly, Hispanic and Asian cultures were often considered to be relatively more conservative and rejecting of homosexuality (Eaton \& Rios, 2016). Duran (2019) also demonstrated that queer students of color might feel disconnected from the queer communities within their university. In the interviews with queer college students of color, one student reported not feeling welcomed to the university's predominantly White queer community. Some reported enjoying the queer people of color student groups on campus, but 
others expressed discomfort with their political and activism-focused orientation. Thus, they chose to find communities that were not related to either race/ethnicity or sexuality such as fraternities/sororities or other interest groups. This finding suggests that queer people of color may find a general sense of acceptance, empathy and common interests supportive and useful.

\section{Present Study}

Due to their double minoritized status identities, queer people of color may experience more discrimination and yet receive less social support (Frost et al, 2016). In addition to discrimination from a wider White heterosexual community, they may face microaggressions and discrimination from their own ethnic and queer communities due to their "othered" identities. Also, they may experience harsher and more derogatory stereotypes, prejudices, and discrimination due to the combined minoritized identities (e.g., an Asian gay male is described as the least manly and attractive compared to Asian men or gay men in general). And yet, social support as buffer against the increased discrimination may be limited because of the intersectional identity. The QPOC (queer people of color) community is relatively small, and if it is oriented for social justice, it may deter some students who find this focus uncomfortable (Duran, 2019). Due to perceived homophobia in their racial/ethnic communities, they may fear losing friends, family, and other immediate support systems that were available for general support and also support for racism-related distress, when and if they disclose their sexuality. Given that literature has documented social support as an important beneficial protective factor for discrimination among people with minoritized status, this perceived lack of support is concerning. Thus, this study addressed the unique challenge of limited social support among queer people of color. To that end, I conceptualized social support into two categories: perceived 
proximal social support from family, friends, and significant others in general, and perceived distal social support from the general communities and society for their identities.

The current study used an intersectional approach to examine whether queer people of color experience more discrimination and higher emotional distress compared to straight people of color. The limited number of the studies compared queer people of color and queer Whites (BrckaLorenz et al, 2019; Balsam et al, 2015), but not straight people of color. To my knowledge, Hayes et al.'s (2011) study was the only study that compared psychological distress among queer students of color, straight students of color, and queer White students. Given the perceived higher level of homophobia in racial/ethnic minority groups and them serving as a crucial support for people of color for addressing racism and maintaining cultural pride, the impact of added sexuality to the racial/ethnic identity needs to be examined by comparing queer people of color and straight people of color.

This study also examined potential buffering roles of social support against the impact of discrimination on emotional distress among queer people of color. In addition, proximal versus distal social support serving differential mitigating roles were explored. It is possible that queer people of color may have a different perception of proximal support from family, friends, and significant others then their perception of the larger community being supportive. Especially for those closeted, their perception of the larger community might affect their perception of how accepting their proximal support might be of their sexuality and cause distress. Additionally, many studies have found that most queer people of color have at least one source of support, or form their own source of support, while also mentioning feeling unaccepted by the larger (heterosexual) ethnic community and (White) queer community (Ghabrial, 2017). However, those who are closeted, or questioning, may be too hyper-aware of others' perceptions to reach 
out to other queer individuals or groups (Fields et al., 2015; Murray et al., 2018). This study examined these unique experiences with social support system among queer people of color by differentiating proximal versus distal social support.

The study hypotheses included the following. H1: Queer people of color would perceive greater discrimination than straight people of color. This hypothesis is based on the multiple minority stress theory by Meyer (2003) that states that those with multiple minority-identities would face higher amounts of stress and discrimination.

H2: Queer people of color would experience greater emotional distress compared to straight people of color. The rationale behind this hypothesis is based on multiple minority stress (Meyer, 2003). In fact, the only study that compared these two groups (Hayes et al., 2011) found that queer people of color reported higher psychological distress compared to straight people of color, although their distress level was not different from that of queer White students.

H3: Queer people of color would perceive similar level of proximal social support in their lives as straight people of color; however, they would experience less perceived distal community social support than straight people of color. While queer people of color receive social support from friends and possibly family (i.e., perceived proximal social support) that help them cope with general stress and also discriminations, they might perceive the larger community as unaccepting of and hostile towards their minoritized identity (i.e., low perceived distal social support). Previous studies showed that some participants had positive relationships with their family, especially over time as the family had time to process and learn about queerness and accept them (Eaton \& Rios, 2017; Rios \& Eaton, 2016). Additionally, queer people of color had accepting friends, especially other queer people of color, who were supportive (Duran, 2019; Frost et al, 2016). However, studies also have reported participants 
feeling disconnected from their ethnic and queer community, along with the existing perception of ethnic communities not being accepting of queerness (Bowleg, 2013; Sadika et al., 2020).

H4: Perceived proximal and distal social support would moderate the association between discrimination and psychological distress among queer people of color, such that for people with higher perceived social support, whether proximal or distal, the association between discrimination and psychological distress would be weaker than for those with lower perceived social support. 


\section{CHAPTER III: METHOD}

\section{Participant Recruitment}

The participants of the study were adults of color. Due to stating this survey as intended for people of color in general, it was hoped that queer participants of color would feel comfortable disclosing their sexuality and reporting their true experiences as queer people of color. A power analysis suggested that the minimum required sample size would be 102 to detect a small effect size at the significance level of .05 and power of .80 for detecting mean differences (i.e., t-test). A minimum sample size required for multiple regression analyses at the significance level of .05 and power of .80 was 311 for a small effect size and 43 for a medium effect size. Multiple methods of recruitment were used. College-wide email were sent to students at Illinois State University as well as University of Illinois- Urbana Champaign. Additionally, a snowball sampling method was used to further spread the survey to other potential participants through my personal connections and those of participants. Personal social media accounts were also used to post recruitment announcements. Participants were incentivized and compensated through the option to opt into a raffle to win one of two $\$ 10$ gift cards. They were led to a separate survey to leave their email address for the raffle such that their email address was not connected to their main survey responses.

\section{Participants}

A total of 401 participants completed the survey. Fifty participants were excluded because they were White and did not meet study inclusion criteria. One additional survey response was excluded due to unusual responding (i.e., their age was 4000 and they identified as an attack helicopter), and 145 responses had significant missing data and were excluded. The final sample of participants of color included in the study were 206. Of the 206 participants, 43 
(20.9\%) were Black or African American, 93 (45.1\%) participants were Asian American or Pacific Islanders, 50 (24.3\%) participants were Latino/Latina/Latinx, $1(.5 \%)$ participant was Native American, and 18 (8.7\%) participants were multiracial. The different ethnicities were grouped together in the study due to limited sample sizes. One participant of color had missing information on race; however, they were included as they were a person of color, and all participants of color were being grouped together for data analysis. Sixty-one (29.8\%) of the participants identified as men, $138(67.0 \%)$ of the participants identified as women, and $5(2.4 \%)$ of the participants identified as nonbinary. The participants ranged from 18 to 69 years in age, ( $M=23.96$ years, $S D=7.61)$. Finally, $188(91.3 \%)$ of the participants reported being in college whereas $17(8.3 \%)$ participants did not.

Additionally, 156 (75.7\%) participants reported their sexuality as heterosexual, 5 (2.4\%) participants reported their sexuality as gay, $3(1.5 \%)$ participants reported their sexuality as lesbian, 27 (13.1\%) participants reported their sexuality as bisexual/pansexual/fluid, $2(1.0 \%)$ participants reported their sexuality as asexual/aromantic, 9 (4.4\%) participants reported their sexuality as queer/questioning, and $4(1.9 \%)$ participants reported their sexuality as Other. There were $50(24.3 \%)$ queer participants of color in the final sample. Majority of participants were from the Midwest region $(\mathrm{N}=168,81.6 \%)$, followed by the West region $(\mathrm{N}=11,5.3 \%)$.

\section{Measures}

Demographic Questions. Participant demographic questions such as age, gender, sexuality, and ethnicity were asked. In addition, how strongly they identify with their racial/ethnic identity and sexuality were measured with one question for each on a sliding scale. Due to the snowball method used, a question about college student status and their regional location was asked. 
Everyday Discrimination Scale (EDS). The EDS was used to measure daily experiences of discrimination (Forman et al., 1997). Each of the nine items was scored on a 6-point Likert scale, ranging from 1 (Never) to 6 (Almost every day). An example question is "[I was] treated with less curtesy than others". The scores were added and averaged to create a single discrimination score, with higher scores indicating more experiences of discrimination. The internal consistency coefficient was reported to be .87 (Clark et al, 2004). The validity was established by finding correlations between experiencing racism and internalizing and externalizing symptoms. The internal consistency coefficient $\alpha$ was .90 in this study.

LGBT-People of Color Microaggression Scale (LGBT-POC MS). The LGBT-POC MS (Balsam et al., 2011) was used to measure the intersectional microaggressions of race and sexuality faced by queer people of color specifically. There are 18 items in the scale with 3 subscales: (a) Racism in LGBT communities (e.g., "Being told that "race isn't important" by White LGBT people"), (b) Heterosexism in Racial/Ethnic Minority Communities (e.g., "Not being accepted by other people of your race/ethnicity because you are LGBT"), and (c) Racism in Dating and Close Relationships (e.g., "Being rejected by potential dating or sexual partners because of your race/ethnicity"). Each item was rated on a 5-point Likert scale ranging from 0 (Did not happen/not applicable to me) to 5 (It happened, and it bothered me extremely). The scores were added and averaged to create a single score, with higher scores indicating more experiences of microaggressions. The total internal consistency coefficient was reported to be .92 (Balsam et al., 2011). Its construct validity was supported by the correlations with psychological distress measures (Balsam et al., 2011). Due to researcher error, 2 items were missing in the survey for the first round of data collection $(\mathrm{N}=102)$. This error was corrected prior to the second round of data collection $(\mathrm{N}=104)$. Using MANOVA testing, we found no significant 
difference between the two samples. Therefore, the two samples were collapsed into one and used for all the analyses. The internal consistency coefficient $\alpha$ was .92 in this study.

K6 Scale. The K-6 scale (Kessler et al., 2002) was developed as a short form scale of the K10 scale to measure psychological distress. This scale was used to measure the distress experienced by people of color when experiencing discrimination. The scale has 6 items that measure distress based on the last 30 days (e.g.: "how often did you feel nervous")/ The items are scored on a 5-point Likert scale, ranging from 1 ("All of the time") to 5 ("None of the time"). The internal coefficient of the scale was 0.89 in the pilot study, establishing the reliability of the scale (Kessler et al., 2002). Discriminant validity was established as the scale is able to be distinguished between and clinical and non-clinical community cases. The internal consistency coefficient $\alpha$ was .88 in this study.

The Multidimensional Scale of Perceived Social Support (MPSS). The MPSS (Zimet et al., 1988) was used to measure perceived social support experienced by close individuals. The MPSS includes 12 items with 3 subscales, each measuring support from a specific personal source of support: (a) significant other (e.g., "There is a special person who is around when I am in need"), (b) family (e.g., "I get the emotional help and support I need from my family"), and (c) friends (e.g., "My friends really try to help me"). Each item is scored on a 6-point Likert scale, ranging from 1 (Very Strongly Disagree) to 6 (Very Strongly Agree). The internal consistency coefficients were reported to be. $91, .87$, and .85 for each subscale respectively and .88 for the total scores (Zimet et al., 1988). Its construct validity was established by negative correlations between the scores and depression and anxiety scores (Zimet et al., 1988). The internal consistency coefficient $\alpha$ was .88 in this study. 
Perceived Community Support Questionnaire (PCSQ). The PCSQ (Herrero \& Garcia, 2007) was used to measure the general distal community support experienced by the participants of color. The scale includes 13 items with 3 subscales that measure different forms of community support: (a) community integrity (e.g., "My opinions are values in my community"), (b) community participation (e.g., "I take part in social activities in my community"), and (c) community organizations (e.g., "I could find people that would help me feel better"). Each item is scaled on a 5-point Likert scale, ranging from 1 (Strongly Disagree) to 5 (Strongly Agree). The internal consistency coefficients were above .86 for the total scores, and ranged between .77 and .88 for each subscale, across multiple samples (Herrero \& Garcia, 2007). Predictive validity was determined by using a depression scale to measure whether the community scales could predict depression scores across time. The researchers found adequate consistency in community and depression scales across time when developing the scale (Herrero \& Garcia, 2007). Due to researcher error, 1 item from this measure also was split into 2 items, which was corrected for the second round of data collection. The internal consistency coefficient $\alpha$ was .82 in this study across all participants.

QPOC Perceived Community Support Scale (QPOC-PCSS). Eight items were created to measure perceived distal social support experienced by queer people of color for this study. The items are provided in the Appendix of the study. Each item is rated on a 5-point Likert scale, ranging from 0 (Never) to 5 (Always). The eight items were: "your larger ethnic community is accepting of your sexuality;" "you are comfortable expressing your sexuality in your larger ethnic community;" "your larger ethnic community has resources that you can use as a queer person of color;" "you are comfortable as a queer person of color in the larger queer community;" "the larger queer community is accepting of your ethnicity;" "the larger queer 
community provides space to express how your race influences your experiences as a queer person;" "the larger queer community has resources you can use as a queer person of color;" and "you are comfortable as a queer person of color in the larger queer community." A pilot sample of queer people of color reviewed the items along with an expert in the field for content validity. The measure was found to be reliable, as the Cronbach's alpha for the scale was .84. The internal consistency for the two subscales was .88 for the distal community support from ethnic community and .84 for distal community support from general queer community.

\section{Data Analytic Procedure}

The first three hypotheses of this study included that queer people of color would perceive higher discrimination (H1) and higher emotional distress (H2) than straight people of color and that queer people of color would perceive similar levels of proximal social support in their lives as straight people of color but would experience lower perceived distal community social support than straight people of color. Using SPSS, four independent $t$-tests were conducted between the queer people of color and straight people of color groups on the four dependent variables (i.e., perceived discrimination, emotional distress, proximal social support, and distal social support). It was expected that (a) mean scores on perceived discrimination and emotional distress would be significantly higher and those on distal social support would be lower for queer people of color than for straight people of color, supporting the double jeopardy theory (Meyer et al., 2003); and (b) there would be no significant mean differences on proximal social support between the two groups.

The last hypothesis stated that perceived proximal and distal social support would moderate the association between discrimination and psychological distress among queer people of color, such that for people with higher perceived social support, whether proximal or distal, 
the association between discrimination and psychological distress would be weaker than for those with lower perceived social support (H4). Therefore, among the queer people of color, a moderated regression analysis was conducted using PROCESS v3.5 (Hayes, 2017), with perceived discrimination as the independent variable, psychological distress as the dependent variable, and perceived proximal support and distal support as two moderator variables. 


\section{CHAPTER IV: RESULTS}

Once data collection was complete, data cleaning and preliminary analysis were conducted. Due to limited sample size, all ethnicities representing people of color were grouped together. Therefore, all heterosexual participants were coded as " $1=$ straight" and all queer participants were coded as " 2 = queer." The participants were also filtered such that White participants were not included in the analysis.

Table 1

Descriptive Statistics for Variables

\begin{tabular}{lcccc}
\hline Variable & $M$ & $S D$ & $\begin{array}{c}\text { Possible } \\
\text { Range }\end{array}$ & $\begin{array}{c}\text { Actual } \\
\text { Range }\end{array}$ \\
& & & & \\
\hline Entire Sample $(N=206)$ & & & & \\
\hline $204 \quad$ Everyday Discrimination & 2.70 & 1.02 & 1.00 & 6 \\
203 Distress & 2.54 & 1.74 & 1.00 & 4.83 \\
203 Loneliness & 2.13 & 2.00 & 1.00 & 4.00 \\
206 General Proximal Social Support & 3.86 & .76 & 1.58 & 5.00 \\
203 General Distal Community Support & 3.34 & 1.77 & 1.33 & 4.64 \\
Queer People of Color (N=50) & & & & \\
$50 \quad$ LGBT-POC Microaggression & 2.88 & .67 & 1.00 & 5.56 \\
$49 \quad$ QPOC Distal Community Support & 2.58 & .70 & 1.00 & 3.63 \\
&
\end{tabular}


Table 1. provides information regarding the means, standard deviations, and range of scores for each measure included in the study. Table 2 presents correlation coefficients among the variables for the entire sample, and Table 3 presents those in the SPOC versus QPOC samples. As expected, general and QPOC discrimination were significantly positively associated with each other. Everyday discrimination for the total sample was significantly associated with distress. General proximal social support (MPSS) for the total sample was negatively associated with distress and everyday discrimination, whereas distal social support (PCSQ) for the total sample was only significantly associated with distress but not with discrimination. For the queer participants of color, most correlation coefficients among variables were not significant. The only significant correlations were between general discrimination and LGBT-POC microaggression $(r=.441, p=.01)$, and between distress and loneliness $(r=-.449, p=.01)$.

Table 2: Correlations Among Variables for the Entire Sample

$\begin{array}{lllll}1 . & 2 . & 3 . & 4 .\end{array}$

1. Everyday

$--.339 * *$

$-$

$.079 \quad .205^{* *}$

Discrimination $.273 * *$

2. Distress

$\begin{array}{lccc}- & - & -.175^{*} & .525 * * \\ & .314^{* *} & \end{array}$

3. General Proximal Social $--\quad .306 * *$ Support $.333 * *$

4. General Distal $--\quad-.156^{*}$ Community Support 
5. Loneliness

Note. $\mathrm{N}=206 ; \mathrm{QPOC} \mathrm{N}=50$

Underside is the correlations for QPOC sample

** Correlation is significant at the 0.01 level (2-tailed)

* Correlation is significant at the 0.05 level (2-tailed).

Table 3: Correlations Among Variables for Straight and QPOC Sample

\begin{tabular}{|c|c|c|c|c|c|c|}
\hline & 1. & 2. & 3. & 4. & 5. & 6. \\
\hline 1. 1. Everyday & -- & $.389 * *$ & - & .081 & $.204 *$ & \\
\hline Discrimination & & & $.261 * *$ & & & \\
\hline 2. Distress & -.069 & -- & - & - & $490 * *$ & \\
\hline & & & $.315^{* *}$ & $.243 * *$ & & \\
\hline 3. General Proximal Social & -.165 & -.106 & -- & $.300 * *$ & - & \\
\hline Support & & & & & $.327 * *$ & \\
\hline 4. General Distal & .254 & .261 & .213 & -- & $-.186^{*}$ & \\
\hline Community Support & & & & & & \\
\hline 5. Loneliness & -.062 & $.449 * *$ & .188 & -.106 & -- & \\
\hline \multirow[t]{2}{*}{ 6. LGBT-POC } & $.441 * *$ & .114 & -.058 & .060 & -- & -- \\
\hline & & & & & & \\
\hline \multirow{2}{*}{$\begin{array}{l}\text { 7. QPOC Distal } \\
\text { Community Support }\end{array}$} & .061 & -.149 & .068 & .009 & .102 & -.101 \\
\hline & & & & & & \\
\hline
\end{tabular}

Note. $\quad \mathrm{SPOC}=156 ; \mathrm{QPOC} \mathrm{N}=50$

Above diagonal are correlation coefficients for the SPOC sample; below diagonal are correlation coefficients for the QPOC sample 
** Correlation is significant at the 0.01 level (2-tailed)

* Correlation is significant at the 0.05 level (2-tailed).

\section{Hypothesis Testing}

Independent sample $t$-tests were conducted to test Hypotheses 1, 2, and 3. H1 stated that queer participants of color would perceive equal or higher level of discrimination than heterosexual participants of color. The $t$-test result supported the hypothesis, $t=-3.14, p=.002$ (see Table 4). H2 stated that queer participants of color would feel higher distress than heterosexual participants of color. The $t$-test result supported the hypothesis, $t=-5.12, p=.000$ (see Table 4)

Table 4

Means, Standard Deviations, and t-scores for Hypothesis 1, 2, and 3

\begin{tabular}{lcccccc}
\hline Variable & HPOC & HPOC & QPOC & QPOC & $t$ & $p$ \\
& $M(S D)$ & $N$ & $M(S D)$ & $N$ & & \\
& & & & & & \\
\hline Discrimination (H1) & $2.58(1.01)$ & 155 & $3.09(.97)$ & 49 & -3.13 & .002 \\
Distress (H2) & $2.37(.85)$ & 155 & $3.09(.76)$ & 48 & -5.19 & .000 \\
Proximal Social Support (H3a) & $3.95(.73)$ & 156 & $3.59(.73)$ & 50 & 3.05 & .003 \\
Distal Social Support (H3b) & $3.40(.51)$ & 154 & $3.15(.60)$ & 49 & 2.88 & .004 \\
\hline
\end{tabular}

Note. $\mathrm{HPOC}=$ Heterosexual People of Color, $\mathrm{QPOC}=$ Queer People of Color

H3a stated that queer participants of color would perceive similar level of proximal social support in their lives as straight participants of color. Contrary to the prediction, heterosexual participants of color reported higher level of perceived proximal social support compared to queer people of color, $t=-3.05, p=.003$ (see Table 4). Supplementary t-tests using the subscale 
scores of the MPSS as dependent variables showed that the two groups differed in the family and significant others subscale scores. Heterosexual participants reported higher level of support from family, $t=3.31, p=.001$, and significant others, $t=2.24, p=.026$, than queer participants of color. $\mathrm{H} 3 \mathrm{~b}$ stated that queer participants of color would perceive lower distal community support than heterosexual participants of color. This hypothesis was supported, $t=-2.88, p=$ .004 (see Table 4).

H4 was that perceived proximal and distal social support would moderate the association between discrimination and psychological distress among queer people of color, such that for people with higher perceived social support, whether proximal or distal, the association between discrimination and psychological distress would be weaker than for those with lower perceived social support. A moderated regression analysis was conducted using PROCESS v3.5 (Hayes, 2017), with perceived discrimination as the independent variable, psychological distress as the dependent variable, and perceived proximal support and distal support as two moderator variables. Contrary to the prediction, the proposed moderated regression model did not predict the distress significantly, $R=.36, R^{2}=.13, F(5,40)=1.2, p=.33$. Specifically, combined racial and sexual discrimination did not predict the felt distress significantly, $\beta=-.08, p=.37$. Neither proximal, $\beta=.02, p=.93$, nor distal support, $\beta=.5, p=.85$. , moderated the association between perceived discrimination and distress. The hypothesis was not supported. 


\section{CHAPTER V: DISCUSSION}

This study examined the distress and discrimination experienced by queer and heterosexual people of color. Based on the multiple minority hypothesis (Meyer et al, 2003) and double jeopardy hypothesis, it was expected that queer people of color would report higher discrimination and higher distress than their heterosexual counterparts. The results supported these hypotheses, providing further support for the multiple minority stress hypothesis, which states that those with multiple minoritized identities/status face more and potentially severe discrimination thus may experience higher level of emotional distress than those who have single minoritized identity. These findings also suggest that those parts of multiple minoritized identities are not rendered invisible due to not being the prototype of the individual identities, as intersectional invisible hypothesis and subordinate male target hypothesis claim (PurdieVaughns, 2008).

\section{Proximal versus Distal Support for Queer People of Color}

Additionally, this study examined the role of social support in lived experiences of queer people of color, based on the previous research that provides evidence for social support to be a protective factor against both racism and heterosexism (e.g.: seeking support is effective in reducing distress from racial discrimination (Brown, 2008); social support for queer individuals is correlated with reduced psychological distress (Frost et. al., 2016). One important contribution of this study was to differentiate between proximal and distal social support and examine both in the context of double minoritized status of queer people of color. Most social support studies in the context of racism or heterosexism use social support from important others including family, friends, and significant other (Balsam et. al., 2011; Eaton \& Rios, 2017; Rios \& Eaton; 2016). Other studies have also discussed the importance of support from the community as a cultural 
sanctuary that provides validation for their identity and support for distress from discrimination for queer people of color (e.g., ethnic community for racism, queer community for heterosexism; Patton, 2011; Frost, 2016). However, few studies (McConnell et al., 2018; Murray et al, 2018) have examined the potentially complicated dynamics of different sources of social support for queer people of color quantitatively. Thus, I hypothesized that queer people of color might receive similar levels of proximal social support from family, friends, and/or significant other but might perceive lower level of support for their identity from communities (i.e., distal support) than heterosexual people of color.

Interestingly, the results showed that queer people of color reported similar levels of support from friends and significant other as straight people of color, but they reported significantly lower level of support from their families. This may indicate that relationships with family members are complicated for queer people of color such that they receive support and microaggressions from the same family members. For example, they may feel supported by their parents when experiencing racism and feel unsupported by them when topics of marriage or gender role expectations are brought up (Rios \& Eaton, 2016). It is possible that earlier generations or older people of color may be more likely to endorse homophobic/transphobic attitudes and may need more time to accept their children's sexuality, and thus parents and adult relatives may actually be a source of microaggression, instead of a source of support, when it comes to sexuality. However, this speculation needs to be tested in future studies. Studies have shown mixed findings on the association between age/generational differences and negative attitudes to sexuality (Piekut et al., 2016; Walch et al., 2010).

As expected, the level of perceived support from friends was not different between the two groups. Perhaps, this means that the friends in the queer participants' lives were accepting 
and supportive of their intersectional identities, as these are individuals that are chosen by the participants to be in their lives as friends and partners. It could also mean that it is more comfortable for the queer participants to have uncomfortable discussions with said groups over family. Particularly in traditional families of color, there may be more hierarchical family structure and pressure for filial piety and deference to the parental authorities, unlike in peer and romantic relationships, that may make speaking about their sexuality against family members difficulty (Eaton \& Rios, 2017; Sadika et al., 2020). This might especially be the case if queer participants of color are partially in the closet, such that their immediate family members are aware and accepting; however, they are asked or choose to remain in the closet for grandparents and extended family due to cultural norms of not risking the parents "loosing face" by them being queer (Durrani \& Sinnacore; 2016; Sadika, 2020). Being in this position might cause a feeling of invalidation from their families.

Contrary to predictions, queer participants of color reported significantly lower support for significant others, despite choosing them similar to friends. This might mean differences in the relationship that queer people of color have with friends verses their partners. It might also imply additional relationship stress in romantic relationships that might cancel some of the support they gain from their partners. For example, those in interracial relationships may experience both interracial and queer romantic stress that heterosexual counterparts only experience the former (Balsam et al., 2011; Sadika, 2020). Finally, not all participants may be in relationships in the present or have had romantic relationships in the past and this subscale may not be applicable to them, thereby skewing the results.

Also consistent with the study hypothesis, queer people of color reported significantly lower levels of perceived support from communities compared straight people of color. It is well 
documented that communities of people of color are homophobic (e.g., same-sex attraction being considered a western influence and not part of their own culture, Sadika et al., 2020) and that queer communities that are predominantly White are racist (e.g., exclusion of queer men of color in gay organizations; Han, 2007). It is important to note that this does not negate homophobia in White communities or imply that ethnic minority communities are inherently more homophobic than White communities. In fact, the sodomy laws in many countries that have criminalized homosexuality were put in place by the British during colonization (Hepple, 2012). Thus, queer people of color may not receive the needed support from their ethnic communities for their sexuality nor from their queer communities for their race/ethnicity. For example, Bowleg (2013) found that $58 \%$ of the Black queer male participants reported heterosexism within Black communities. While 7 out of 12 reported being out to family and friends, most of the participants reported a common theme of perceiving Black communities to be unaccepting and feeling a pressure to be masculine to "hide the gay". Ghabrial (2017) similarly reported that the queer participants reported a common theme of not being represented or accepted in predominantly White queer spaces and reported being distant or isolated from their ethnic community due to perceived unacceptance of their sexuality. Queer people of color have different levels of outness that could cause distress due to not knowing how people in their life might react. When they are not out, they still might experience microaggression (e.g., sexual slurs) from their ethnic community. When they are out, they may be more blatantly alienated or harassed due to their sexuality.

Similarly, qualitative studies reported that queer people of color also experience racism within predominantly White queer spaces (Duran, 2019; Sadika, 2020; Ghabrial, 2017). McConnel et al. (2018) found that experiencing racial stigma in queer spaces was associated 
with heightened level of stress among queer men of color. Thus, the queer community that could provide support for their sexuality in fact may marginalize queer people of color. Taken together, the queer community or racial/ethnic community at large may not be perceived as supportive of their double minoritized identities.

This study was one of the first to differentiate proximal and distal support; however, it did not compare the queer vs. ethnic community in their role of providing distal social support. This comparison is important for future research. Because race is viewed as a primary identity for many queer people of color, through which other identities are experienced (Bowleg, 2013), racism and thus lack of support from queer communities may be more detrimental. Or, for the same reason, experiencing heterosexism within their ethnic communities can be more difficult (Bowleg, 2013), because ethnic communities and related religious communities (e.g., churches) are a crucial source of support against racial discrimination (Brown, 2008) and many QPOC must navigate being out and not losing vital sources of support (Murray et al., 2018; Sadika et al, 2020). In fact, Sadika et al (2020) found that many queer participants of color felt distress due to conflict between freedom of exploration of their sexuality and wanting their family close. Future studies may explore the relative importance of queer vs. ethnic community in providing needed support for queer people of color.

\section{Social Support Not Buffering Impact of Discrimination for Queer People of Color}

The hypothesis that proximal and distal social support would moderate the relationship between discrimination and distress was not supported. Contrary to the study prediction perceived social support did not appear to buffer against the impact of discrimination on felt emotional distress for queer people of color. This result can be interpreted in several ways. First, this may mean that the social support received by queer people of color is not sufficient in 
reducing the emotional distress caused by discrimination. In fact, this result is consistent with McConnel et al.'s (2018) finding that connection with the queer community did not moderate the relationship between experiencing racial stigma in queer spaces and stress among queer men of color. Other protective factors (e.g., minority coping, Meyer, 2015) may need to be identified and capitalized on in serving queer people of color. Second, the current conceptualization of social support may not have captured the type or nature of social support that does help in buffering against the doubled discrimination for queer people of color. For example, many qualitative studies reported that participants created their own community of other queer people of color (Ghabrial, 2017; Duran, 2019). This community may be smaller but could provide validations and comfort for the unique challenges of having double minoritized status. It is possible that the existence of this type of space and support may indeed buffer against the impact of discrimination. This speculation needs to be tested in future studies.

Third, the conceptualization of distal social support as proposed by this study may have been confounded with microaggression (e.g., microinvalidation) conceptually. It is possible that the distal support scale that was developed for this study did not adequately capture the unique experience of both support and invalidation by the same individuals and communities due to the multiple minoritized identities. Fourth, the current global pandemic and increased racism (i.e., Asian hate crimes, police brutality against Black community) at the time of data collection may have temporarily affected participants' perception of social support from communities, and a possible increase in seeking support for their ethnic identities. It might be that White queer individuals and White queer spaces felt unwelcoming due to heightened awareness of increased racism. Many sources of support in communities were also not accessible such as church, support groups, meetings for organizations, or even simply meeting friends and/or family due to 
social distancing and COVID 19 precautions. Alternatively, it is possible that those living with parents or in the closet did not have the space to explore their sexuality that they previously had in college and out-of-home options. Finally, the sample size was small for the QPOC sample which might have resulted in the lack of moderating effects. Therefore, this speculation needs to be tested in future studies.

\section{Clinical Implications}

The results of this study suggest five clinical implications for counselors who serve queer people of color. First, this study demonstrated that queer people of color face intersectional discrimination for their queerness and their race/ethnicity, which may be both qualitatively and quantitatively different from racial or sexual discrimination alone. It is crucial to acknowledge and validate this unique challenge for queer people of color. Second, support systems as conceptualized in this study were not found to be a protective factor for the participants of this study. Counselors are suggested to explore the nature and existence of social support that would be helpful for their queer clients of color and other protective factors that could buffer against discrimination.

Third, the results also suggests that queer people of color may benefit from therapy focusing on their relationship with their family and their perceptions of family support. Given the lower level of perceived familial support, for example, finding family members who could be allies and supports (e.g., siblings) could be potentially protective against the impact of homophobic relatives. It is also suggested that finding other people of color who are part of the queer community or who are accepting and creating micro-communities might help bridge the perceived lack of support from their larger ethnic community. Fourth, counselors may help clients reflect with critical consciousness on their identification with and attitudes towards their 
ethnicity in the context of their ethnic communities' attitudes towards sexuality and their history of embracing and accepting sexual minorities. This would help clients negotiate and integrate conflicting attitudes towards different dimensions of one's identity from different groups with which they identify. Exploration of the history of non-binary identities and queerness in the history of their communities that was erased due to White puritan views and colonization, and the process of decolonization that recognizes and embraces this history and existence of sexualities and genders might also help in reducing feelings of isolation from the community and internalized ideas of non-straightness being western ideologies, a view prominent in many ethnic communities (Sadika, 2020). Finally, group counselors should explore community/cultural coping that involves components such as collectivism, radical hope, cultural authenticity and self-knowledge (French et al., 2020) to help queer people of color explore their experiences though community support that might be low in their personal lives.

\section{Strengths, Limitations and Future Research}

One contribution of this study was to fill a gap in the literature by comparing heterosexual and queer people of color. Previous studies have mostly compared queer people of color with White queer individuals. They have found that, although queer people of color reported higher discrimination, White queer individuals reported similar or higher distress than queer people of color (Hayes et al., 2011), which was not consistent with the double jeopardy hypothesis. By comparing heterosexual versus queer people of color, this study clarified that double minoritized status does increase not only perceived discrimination but also psychological distress. Comparing sexuality among people of color was crucial because race is viewed as a primary identity through which other identities are experienced for many people of color (Bowleg et al., 2013). Some people of color are also provided with racial socialization from a 
young age to help cope with racial discrimination that is assumed to be used to help cope with heterosexist discrimination by queer people of color (Brown, 2008), which may be partly why queer people of color did not report any higher distress than white people of color (Hayes et al., 2011). However, queer people of color experience increased distress compared to straight people of color, highlighting the toll that queerness takes on people of color despite their coping resources against discrimination.

This study supported the double jeopardy hypothesis in the context of intersectionality between race/ethnicity and sexuality. Future studies should further examine how race intersects with other identities such as gender identity (e.g., transgender and non-gender conforming identity). More scholarly attention is particularly needed on non-binary and trans people of color given the highest rates of violence perpetuated against them (Dino, 2017; Human Right Campaign). They experience discrimination from White and POC cisgender-heterosexual communities as well as White and POC cisgender-LGB communities.

Another contribution of this study was to conceptualize social support as proximal (i.e., the specific individuals that queer people of color gain support from like family, friends, and significant others) and distal (i.e., perceived social support from their ethnic community as a whole), based on the unique supportive roles that ethnic and queer communities play for racial/ethnic and sexual minorities. This study did find the overall lower level of support from family and did confirm the limited community support for queer people of color due to their intersectional identities. This result elucidated the complicated nature of social support for queer people of color.

Despite these marked strengths, this study has some limitations that are worth mentioning. First, two items from Perceived Community Support Questionnaire and one item 
from the LGBT-POC Microaggression Scale were omitted from the survey mistakenly in the first round of data collection $(\mathrm{N}=102)$. This error was corrected in the second round $(\mathrm{N}=104)$. A MANOVA between the first and second samples on the study variables did not show any significant group differences. Therefore, the two samples were collapsed into one and used for the data analyses of this study. Second, the sample size of queer people of color was small for detecting a small effect size, which might have contributed to the non-significant regression findings. Also, the sample size did not allow for comparisons between social support from ethnic groups and sexual orientations. Future research should examine whether the two types of supports play different levels of moderating effects across the different sexual orientations and ethnicities with a larger sample. Third, the scale that was developed for this study to measure distal community support for queer people of color needs further validation. As discussed, the current scale might not be nuanced enough to fully capture the relationships of queer people of color and the ways they receive support from individuals and communities. Finally, the participants of the study were mostly from the Midwest and the results may not be generalizable to queer people of color in other regions (e.g., areas that have more open attitudes towards queer identities or racial minorities than the Midwest at an aggregate level).

\section{Conclusion}

In conclusion, queer people of color have multiple minoritized identities and experience multiple forms of discrimination due to their individual minority identities or intersectional identities. Due to their intersectional identities, queer people of color may experience discrimination within their larger single-minority identities (their predominantly straight ethnic communities and predominantly White queer communities). Social support is a vital factor in buffering the distress experienced from discrimination; however, queer people of color may have 
fewer sources of support who understand their unique experiences. This study aimed to examine the levels of discrimination and distress experienced by queer people of color and examine the levels of perceived social support from both individuals in their life, and from their larger community. Results of the study supported the hypothesis of queer people of color having higher discrimination, higher distress, and lower social support than heterosexual counterparts. The hypothesis that social support plays a buffering role on the relationship between discrimination and distress was not supported by the regression analyses. More research is needed to find factors in queer people of colors' lives that help reduce distress. 


\section{REFERENCES}

Asakura, K. (2017). Paving pathways through the pain: A grounded theory of resilience among lesbian, gay, bisexual, trans, and queer youth. Journal of Research on Adolescence, 27(3), 521-536.

Balsam, K. F., Molina, Y., Beadnell, B., Simoni, J., \& Walters, K. (2011). Measuring multiple minority stress: the LGBT People of Color Microaggressions Scale. Cultural Diversity and Ethnic Minority Psychology, 17(2), 163-174.

Beauchaine, T. P., Mickey, R. M., \& Rothblum, E. D. (2005). Mental health of lesbian, gay, bisexual, and heterosexual siblings: Effects of gender, sexual orientation, and family. Journal of Abnormal Psychology, 114(3), 471-476.

Beemyn, G. (2013). A presence in the past: A transgender historiography. Journal of Women's History, 25(4), 113-121.

Bonilla-Silva, E., \& Dietrich, D. (2011). The sweet enchantment of color-blind racism in Obamerica. The ANNALS of the American Academy of Political and Social Science, 634(1), 190-206.

Bos, H. M., Sandfort, T. G., De Bruyn, E. H., \& Hakvoort, E. M. (2008). Same-sex attraction, social relationships, psychosocial functioning, and school performance in early adolescence. Developmental Psychology, 44(1), 59-68.

Brondolo, E., Ver Halen, N. B., Pencille, M., Beatty, D., \& Contrada, R. J. (2009). Coping with racism: A selective review of the literature and a theoretical and methodological critique. Journal of Behavioral Medicine, 32(1), 64-88.

Brown, D. L. (2008). African American resiliency: Examining racial socialization and social support as protective factors. Journal of Black Psychology, 34(1), 32-48. 
Bowleg, L. (2013). “Once you've blended the cake, you can't take the parts back to the main ingredients": Black gay and bisexual men's descriptions and experiences of intersectionality. Sex Roles, 68(11-12), 754-767.

Burgess, D., Lee, R., Tran, A., \& Van Ryn, M. (2007). Effects of perceived discrimination on mental health and mental health services utilization among gay, lesbian, bisexual and transgender persons. Journal of LGBT Health Research, 3(4), 1-14.

Chatelain, M., \& Asoka, K. (2015). Women and Black lives matter. Dissent, 62(3), 54-61.

Christian, T. Y. (2005). "Good Cake": An ethnographic trilogy of life satisfaction among gay Black men. Men and Masculinities, 8(2), 164-174.

Clements-Nolle, K., Marx, R., Guzman, R., \& Katz, M. (2001). HIV prevalence, risk behaviors, health care use, and mental health status of transgender persons: Implications for public health intervention. American Journal of Public Health, 91(6), 915-921.

Cooper, B. (2018). Eloquent rage: A Black feminist discovers her superpower. St. Martin's Press.

Crandall, C. S., Miller, J. M., \& White, M. H. (2018). Changing norms following the 2016 US presidential election: The Trump effect on prejudice. Social Psychological and Personality Science, 9(2), 186-192.

Crenshaw, K. (1989). Demarginalizing the intersection of race and sex: A black feminist critique of antidiscrimination doctrine, feminist theory and antiracist politics. University of Chicago Legal Forum, 1989(1), 139-167.

Dinno, A. (2017). Homicide rates of transgender individuals in the United States: 20102014. American Journal of Public Health, 107(9), 1441-1447. 
Doty, N. D., Willoughby, B. L., Lindahl, K. M., \& Malik, N. M. (2010). Sexuality related social support among lesbian, gay, and bisexual youth. Journal of Youth and Adolescence, 39(10), 1134-1147.

Duran, A. (2019). A photovoice phenomenological study exploring campus belonging for queer students of color. Journal of Student Affairs Research and Practice, 56(2), 153-167.

Duran, A. (2019). "Outsiders in a niche group": Using intersectionality to examine resilience for queer students of color. Journal of Diversity in Higher Education.14(2), 1-11

Durrani, S., \& Sinacore, A. L. (2016). South Asian-Canadian gay men and HIV: Social, cultural, and psychological factors that promote health/Hommes gais canadiens d'origine asiatique du sud et VIH: Facteurs sociaux, culturels, et psychologiques qui favorisent des comportements de sante. Canadian Journal of Counselling and Psychotherapy (Online), 50(2), 164-179.

Eaton, A. A., \& Rios, D. (2017). Social challenges faced by queer Latino college men: Navigating negative responses to coming out in a double minority sample of emerging adults. Cultural Diversity and Ethnic Minority Psychology, 23(4), 457-467

Emmerich, R. (2015) Stonewall, Roadside Attractions, Los Angeles. Movie

Fields, E. L., Bogart, L. M., Smith, K. C., Malebranche, D. J., Ellen, J., \& Schuster, M. A. (2015). "I always felt I had to prove my manhood": Homosexuality, masculinity, gender role strain, and HIV risk among young Black men who have sex with men. American Journal of Public Health, 105(1), 122-131.

French, B. H., Lewis, J. A., Mosley, D. V., Adames, H. Y., Chavez-Dueñas, N. Y., Chen, G. A., \& Neville, H. A. (2020). Toward a psychological framework of radical healing in communities of color. The Counseling Psychologist, 48(1), 14-46. 
Frye, M. (1983). Oppression. The politics of reality: Essays in feminist theory. Reprinted in $V$. Taylor, N. Whittier, and L. Rupp (Eds.) Feminist frontiers.

Ghabrial, M. A. (2017). "Trying to figure out where we belong”: Narratives of racialized sexual minorities on community, identity, discrimination, and health. Sexuality Research and Social Policy, 14(1), 42-55.

Han, C. S. (2006). Geisha of a different kind: Gay Asian men and the gendering of sexual identity. Sexuality and Culture, 10(3), 3-28.

Han, C. S. (2007). They don't want to cruise your type: Gay men of color and the racial politics of exclusion. Social Identities, 13(1), 51-67.

Han, C. S., Proctor, K., \& Choi, K. H. (2014). I know a lot of gay Asian men who are actually tops: Managing and negotiating gay racial stigma. Sexuality \& Culture, 18(2), 219-234.

Human Rights Campaign (2020). Fatal violence against transgender and gender nonconforming people in The United States in 2020. Human Rights Campaign.Website

Hayes, J. A., Chun-Kennedy, C., Edens, A., \& Locke, B. D. (2011). Do double minority students face double jeopardy? Testing minority stress theory. Journal of College Counseling, 14(2), 117-126.

Hefner, J., \& Eisenberg, D. (2009). Social support and mental health among college students. American Journal of Orthopsychiatry, 79(4), 491-499.

Henry, J. D., \& Crawford, J. R. (2005). The 21-item version of the Depression Anxiety Stress Scales (DASS-21): Normative data and psychometric evaluation in a large non-clinical sample. British Journal of Clinical Psychology, 44, 227-239.

Hepple, J. (2012). Will sexual minorities ever be equal? The repercussions of British colonial “sodomy" laws. The Equal Rights Review, 8, 50-64. 
Hoffman, B. (2014). An overview of depression among transgender women. Depression Research and Treatment (2014), 1-9.

House, J. S., Umberson, D., \& Landis, K. R. (1988). Structures and processes of social support. Annual Review of Sociology, 14(1), 293-318.

Ifatunji, M. A., \& Harnois, C. E. (2016). An explanation for the gender gap in perceptions of discrimination among African Americans: Considering the role of gender bias in measurement. Sociology of Race and Ethnicity, 2(3), 263-288.

Jefferson, K., Neilands, T. B., \& Sevelius, J. (2013). Transgender women of color: Discrimination and depression symptoms. Ethnicity and Inequalities in Health and Social Care, 6(4), 121-136.

Kehrer, L. (2018). A love song for all of us?: Macklemore's "same love" and the myth of black homophobia. Journal of the Society for American Music, 12(4), 425-448.

Kessler, R. C., Andrews, G., Colpe, L. J., Hiripi, E., Mroczek, D. K., Normand, S. L., Walters, E. E., \& Zaslavsky, A. M. (2002). Short screening scales to monitor population prevalences and trends in non-specific psychological distress. Psychological Medicine, 32(6), 959976.

Krieger, N. (1999). Embodying inequality: A review of concepts, measures, and methods for studying health consequences of discrimination. International Journal of Health Services, 29(2), 295-352.

Liu, R. T., \& Mustanski, B. (2012). Suicidal ideation and self-harm in lesbian, gay, bisexual, and transgender youth. American Journal of Preventive Medicine, 42(3), 221-228.

Mays, V. M., Cochran, S. D., \& Rhue, S. (1993). The impact of perceived discrimination on the intimate relationships of Black lesbians. Journal of Homosexuality, 25, 1-14. 
McClain, S., Beasley, S. T., Jones, B., Awosogba, O., Jackson, S., \& Cokley, K. (2016). An examination of the impact of racial and ethnic identity, impostor feelings, and minority status stress on the mental health of Black college students. Journal of Multicultural Counseling and Development, 44(2), 101-117.

McConnell, E. A., Janulis, P., Phillips, I. I., Truong, R., \& Birkett, M. (2018). Multiple minority stress and LGBT community resilience among sexual minority men. Psychology of Sexual Orientation and Gender Diversity, 5(1), 1-12.

Meidlinger, P. C., \& Hope, D. A. (2014). Differentiating disclosure and concealment in measurement of outness for sexual minorities: The Nebraska Outness Scale. Psychology of Sexual Orientation and Gender Diversity, 1(4), 489-497.

Meyer, I. H. (2003). Prejudice, social stress, and mental health in lesbian, gay, and bisexual populations: conceptual issues and research evidence. Psychological Bulletin, 129(5), 674-697.

Meyer, I. H. (2015). Resilience in the study of minority stress and health of sexual and gender minorities. Psychology of Sexual Orientation and Gender Diversity, 2(3), 209-213.

Murray, A., Gaul, Z., Sutton, M. Y., \& Nanin, J. (2018). "We hide...”: perceptions of HIV risk among Black and Latino MSM in New York City. American Journal of Men's Health, 12(2), 180-188.

Mustanski, B., Newcomb, M. E., \& Garofalo, R. (2011). Mental health of lesbian, gay, and bisexual youths: A developmental resiliency perspective. Journal of Gay \& Lesbian Social Services, 23(2), 204-225. 
Mustanski, B., \& Liu, R. T. (2013). A longitudinal study of predictors of suicide attempts among lesbian, gay, bisexual, and transgender youth. Archives of Sexual Behavior, 42(3), $437-$ 448.

Parmenter, J. G., Galliher, R. V., \& Maughan, A. D. (2020). LGBTQ+ emerging adults' perceptions of discrimination and exclusion within the LGBTQ+ community. Psychology \& Sexuality, 1-16. DOI: $10.1080 / 19419899.2020 .1716056$

Patton, L. D. (2011). Perspectives on identity, disclosure, and the campus environment among African American gay and bisexual men at one historically Black college. Journal of College Student Development, 52(1), 77-100.

Peteet, B. J., Brown, C. M., Lige, Q. M., \& Lanaway, D. A. (2014). Impostorism is associated with greater psychological distress and lower self-esteem for African American students. Current Psychology, 34, 1-10.

Pittman, D. M., Riedy Rush, C., Hurley, K. B., \& Minges, M. L. (2020). Double jeopardy: Intimate partner violence vulnerability among emerging adult women through lenses of race and sexual orientation. Journal of American College Health (65), 1-9.

Pratto, F., Sidanius, J., \& Levin, S. (2006). Social dominance theory and the dynamics of intergroup relations: Taking stock and looking forward. European Review of Social Psychology, 17(1), 271-320.

Purdie-Vaughns, V., \& Eibach, R. P. (2008). Intersectional invisibility: The distinctive advantages and disadvantages of multiple subordinate-group identities. Sex Roles, 59(56), 377-391. 
Ramirez, J. L., \& Paz Galupo, M. (2019). Multiple minority stress: The role of proximal and distal stress on mental health outcomes among lesbian, gay, and bisexual people of color. Journal of Gay \& Lesbian Mental Health, 23(2), 145-167.

Ratts, M. J. (2017). Charting the center and the margins: Addressing identity, marginalization, and privilege in counseling. Journal of Mental Health Counseling, 39(2), 87-103.

Rios, D., \& Eaton, A. (2016). Perceived social support in the lives of gay, bisexual and queer Hispanic college men. Culture, Health \& Sexuality, 18(10), 1093-1106.

Sadika, B., Wiebe, E., Morrison, M. A., \& Morrison, T. G. (2020). Intersectional microaggressions and social support for LGBTQ persons of color: A systematic review of the Canadian-based empirical literature. Journal of GLBT Family Studies, 16(2), 111147.

Salvatore, J., \& Shelton, J. N. (2007). Cognitive costs of exposure to racial prejudice. Psychological Science, 18(9), 810-815.

Schmitt, M. T., \& Branscombe, N. R. (2002). The meaning and consequences of perceived discrimination in disadvantaged and privileged social groups. European Review of Social Psychology, 12(1), 167-199.

Shilo, G., \& Mor, Z. (2014). The impact of minority stressors on the mental and physical health of lesbian, gay, and bisexual youths and young adults. Health \& Social Work, 39(3), 161171.

Steele, C. (1997). A threat in the air: How stereotypes shape intellectual identity and performance. American Psychologist, 52, 613-629. 
Stein, H. F., \& Allcorn, S. (2018). A fateful convergence: Animosity toward Obamacare, hatred of Obama, the rise of Donald Trump, and overt racism in America. Journal of Psychohistory, 45(4), 234-243.

Stone, A. L., \& Ward, J. (2011). From 'Black people are not a homosexual act' to 'gay is the new Black': Mapping white uses of Blackness in modern gay rights campaigns in the United States. Social Identities, 17(5), 605-624.

Su, J., Kuo, S. I., Derlan, C. L., Hagiwara, N., Guy, M. C., \& Dick, D. M. (2020). Racial discrimination and alcohol problems among African American young adults: Examining the moderating effects of racial socialization by parents and friends. Cultural Diversity and Ethnic Minority Psychology, 26(2), 260-270.

Sue, D. W., Capodilupo, C. M., Torino, G. C., Bucceri, J. M., Holder, A., Nadal, K. L., \& Esquilin, M. (2007). Racial microaggressions in everyday life: Implications for clinical practice. American Psychologist, 62(4), 271-286.

Velez, B. L., Polihronakis, C. J., Watson, L. B., \& Cox Jr, R. (2019). Heterosexism, racism, and the mental health of sexual minority people of color. The Counseling Psychologist, 47(1), 129-159.

Ward, E. G. (2005). Homophobia, hypermasculinity and the US black church. Culture, Health \& Sexuality, 7(5), 493-504.

White, C. R., \& Jenkins, D. D. (2017). College students' acceptance of trans women and trans men in gendered spaces: The role of physical appearance. Journal of Gay \& Lesbian Social Services, 29(1), 41-67. 
Wilson, P. A., Valera, P., Ventuneac, A., Balan, I., Rowe, M., \& Carballo- Dié guez, A. (2009). Race-based sexual stereotyping and sexual partnering among men who use the internet to identify other men for bareback sex. Journal of Sex Research, 46, 399-413

Zimet, G. D., Dahlem, N. W., Zimet, S. G., \& Farley, G. K. (1988). The multidimensional scale of perceived social support. Journal of Personality Assessment, 52(1), 30-41. 


\section{APPENDIX: DISTAL PERCEIVED COMMUNITY SUPPORT SCALE (DPCSS)}

\section{Appendix. Distal Perceived Community Support Scale (DPCSS)}

Instructions: Please rate the following questions based on your experiences with your larger ethnic and sexual community as a queer person of color. If you are not out, please answer the questions based on how you view the larger ethnic and sexual community might interact with you knowing you are a queer person of color.

The rating scale is as follows:

1: Never

2: Very Rarely

3: Sometimes

4: Very Often

5: Always

\begin{tabular}{|c|c|c|c|c|c|}
\hline How often do you feel like: & 1 & 2 & 3 & 4 & 5 \\
\hline $\begin{array}{l}\text { 1. your larger ethnic community is accepting of your } \\
\text { sexuality }\end{array}$ & 1 & 2 & 3 & 4 & 5 \\
\hline $\begin{array}{l}\text { 2. you are comfortable expressing your sexuality in } \\
\text { your larger ethnic community }\end{array}$ & 1 & 2 & 3 & 4 & 5 \\
\hline $\begin{array}{l}\text { 3. your larger ethnic community has resources that } \\
\text { you can use as a queer person of color. }\end{array}$ & 1 & 2 & 3 & 4 & 5 \\
\hline
\end{tabular}




\begin{tabular}{|c|c|c|c|c|c|}
\hline $\begin{array}{l}\text { 4. you are comfortable as a queer person of color in } \\
\text { the larger queer community }\end{array}$ & 1 & 2 & 3 & 4 & 5 \\
\hline $\begin{array}{l}\text { 5. the larger queer community is accepting of your } \\
\text { ethnicity }\end{array}$ & 1 & 2 & 3 & 4 & 5 \\
\hline $\begin{array}{l}\text { 6. the larger queer community provides space to } \\
\text { express how your race influences your experiences } \\
\text { as a queer person. }\end{array}$ & 1 & 2 & 3 & 4 & 5 \\
\hline $\begin{array}{l}\text { 7. The larger queer community has resources you can } \\
\text { use as a queer person of color. }\end{array}$ & 1 & 2 & 3 & 4 & 5 \\
\hline $\begin{array}{l}\text { 8. You are comfortable as a queer person of color in } \\
\text { the larger queer community }\end{array}$ & 1 & 2 & 3 & 4 & 5 \\
\hline
\end{tabular}

